\title{
A Triad of Ketoacidosis, Hypertriglyceridemia, and Acute Pancreatitis Associated With Sugar- Sweetened Soft Drinks Abuse in a Caucasian Patient With Undiagnosed Type 2 Diabetes Mellitus
}

\author{
Alessandra Vitelli ${ }^{1}$, Valentina Apuzzi ${ }^{1}$, Francesco Calderaro Sr. ${ }^{2}$, Olimpia Fattoruso ${ }^{3}$, Vincenzo Bassi ${ }^{4}$ \\ 1. U.O.C. Medicina Generale E Lungodegenza, San Giovanni Bosco, Asl Napoli 1 Centro, Naples, ITA 2. U.O.C. Medicina \\ Genereale E Lungodegenza, San Giovanni Bosco, Asl Napoli 1 Centro, Naples, ITA 3. Pathology, San Giovanni Bosco \\ Hospital, ASL Napoli 1 Centro, Naples, ITA 4. U. O. C. Di Medicina Generale E Lungodegenza, San Giovanni Bosco \\ Hospital, Asl Napoli 1 Centro, Naples, ITA
}

Corresponding author: Alessandra Vitelli, alessandra.vitelli1982@gmail.com

\begin{abstract}
A 24-year-old obese Caucasian male, without relevant anamnesis, who was admitted to the ER presented with abdominal pain, nausea and vomiting, hyperglycemia, and diabetic ketoacidosis (DKA). The diagnosis of acute pancreatitis (AP) was supported by increased serum levels of triglycerides and lipase associated with abdominal CT scans. The patient was treated for five days with IV regular insulin, hydration, electrolytes replacement, and statin/fibrate therapy with clinical improvement. Some $10 \%$ hemoglobin A1c value, normal C-peptide level and negative glutamic acid decarboxylase (GAD-65), and islet cell autoantibodies suggested the diagnosis of a new-onset type 2 diabetes mellitus (DM) presenting with an uncommon triad of DKA and hypertriglyceridemia (HTG)-induced AP. Anamnestic history suggested that DKA was dependent on sugar-sweetened soft drinks abuse (soft drink ketosis), a clinical association more frequent in Asian than in Western patients.
\end{abstract}

Categories: Endocrinology/Diabetes/Metabolism, Internal Medicine, Gastroenterology

Keywords: diabetes mellitus, ketoacidosis, hypertriglyceridemia, acute pancreatitis, soft drinks, western patient

\section{Introduction}

Diabetic ketoacidosis (DKA) is an emergency condition characterized by hyperglycemia, metabolic acidosis, and hyperketonemia. Usually, DKA is secondary to an absolute insulin deficiency typical of type 1 diabetes mellitus (DM); however, DKA could be rarely seen in patients with type 2 DM when a relative pancreatic $\beta$ cell dysfunction occurs [1-4]. Insulin deficiency induces both glucose and lipid metabolism dysregulation, such as hyperglycemia and hypertriglyceridemia (HTG) [5-7]. Usually, serum triglycerides (TG) value > 1000 $\mathrm{mg} / \mathrm{dL}$ is responsible for four percent of overall acute pancreatitis (AP) secondary to toxic free fatty acids (FFA) from TG breakdown [8-9]. Moreover, in Eastern countries, an increasing number of case reports of DKA from both type 1 and type $2 \mathrm{DM}$ are described as secondary to sugar-sweetened soft drinks overconsumption (soft drink ketosis) [6, 10-13].

Received 04/23/2020

Review ended 05/05/2020 Published 05/26/2020

\section{(c) Copyright 2020}

Vitelli et al. This is an open access article distributed under the terms of the Creative Commons Attribution License CC-BY 4.0., which permits unrestricted use, distribution, and reproduction in any medium, provided the original author and source are credited.

\section{Case Presentation}

A 24-year-old obese Italian male (body mass index $=48.9 \mathrm{~kg} / \mathrm{m} 2$ ) was admitted to our ER Unit presenting with abdominal epigastric pain and persistent nausea with vomiting in the last four days. Medical history was negative to alcohol abuse, cholelithiasis, dyslipidemia, or drug therapy; however, familiar history of hypertriglyceridemia (mother and maternal grandfather) was reported. Four liters daily intake of sugarsweetened soft drinks was referred. On clinical examination, the patient presented with severe abdominal pain without epigastric resistance and negative Murphy's sign, tachyarrhythmia (heart rate=120 beats/min), hyperthermia $\left(38^{\circ} \mathrm{C}\right)$, severe dehydration, and Kussmaul breathing. Laboratory parameters clearly showed metabolic acidosis, hyperglycemia, increased $\mathrm{Hb}$ A1c value, and severe $\mathrm{HTG}$ resulting in lactescent serum. Normal serum values of C-peptide, glutamic acid decarboxylase (GAD-65), and islet cell autoantibodies suggested the diagnosis of new-onset type 2 DM (Table 1). Abdominal CT scans showed an edematous AP. The patient's DKA was treated for five days with regular insulin IV infusion associated with aggressive fluid replacement starting with normal saline solution, then a $10 \%$ glucose solution after a gradual decrease of glycemia and potassium supplementation [14]. Fenofibrate (145 mg orally, twice a day) and atorvastatin (20 mg once a day) were started obtaining a fast HTG decrease ( $<500 \mathrm{mg} / \mathrm{dL}$ in about 72 hours) excluding the need of plasmapheresis. A gradual decrease of serum glucose levels, ketones, and TG were observed (Table 2). A low-calorie diet was introduced and insulin IV therapy was interrupted, starting a basal bolus insulin regimen when hyperglycemia, metabolic acidosis, and hyperketonemia were corrected and epigastric pain disappeared. CT scan and serum lipase values normalized in about 45 days. The patient was discharged on the 23rd day with basal-bolus insulin regimen, metformin, atorvastatin, fibrates, omega-3 therapy 


\section{Cureus}

suggesting a fat-restricted diet.

\begin{tabular}{|c|c|}
\hline Laboratory parameters & Values \\
\hline $\mathrm{HbA1c}(<6.5 \%)$ & 10.9 \\
\hline Serum glucose $(60-110 \mathrm{mg} / \mathrm{dL})$ & 324 \\
\hline C-peptide (0.9-7.1 ng/mL) & 4.7 \\
\hline Glutamic acid decarboxylase (GAD-65) autoantibodies ( $<5 \mathrm{U} / \mathrm{mL}$ ) & $<5$ \\
\hline Islet cell autoantibodies $(<1: 4)$ & $<1: 4$ \\
\hline Amylase (28-100 Ul/L) & 80 \\
\hline Lipase (13-60 UI/L) & 554 \\
\hline Total cholesterol (<200 mg/dL) & 596 \\
\hline Triglycerides (<200 mg/dL) & 4797 \\
\hline Ketonemia (<0.6 $\mu \mathrm{mol} / \mathrm{L})$ & 4.5 \\
\hline Uric acid (3.4-7.0 mg/dL) & 10.9 \\
\hline $\mathrm{Na}(135-148 \mathrm{mEq} / \mathrm{L})$ & 131 \\
\hline $\mathrm{K}(3.6-5.3 \mathrm{mEq} / \mathrm{L})$ & 4.7 \\
\hline WBC $(4.000-11.000 / \mathrm{mm})$ & 18500 \\
\hline Micro albuminuria (<1.9 mg/dL) & 18.39 \\
\hline PCR (<0.5 mg/dL) & 48,7 \\
\hline $\mathrm{Ph}(7.35-7.45)$ & 7.27 \\
\hline SPO2 (>90\%) & 99 \\
\hline PaCO2 (35-45 mmHg) & 14 \\
\hline $\mathrm{PaO} 2(80-100 \mathrm{mmHg})$ & 88 \\
\hline HCO3- (22-26 mmol/L) & 6 \\
\hline Base excess (>-2<+2 mmol/L) & -20.9 \\
\hline Lactate $(0.3-1.2 \mathrm{mmo} / \mathrm{L})$ & 0.8 \\
\hline Anion gap & 22 \\
\hline
\end{tabular}

\section{TABLE 1: Initial laboratory data.}

\begin{tabular}{|l|l|l|l|l|l|l|}
\hline Lab test & At admission & $24 \mathrm{~h}$ & $\mathbf{4 8} \mathrm{h}$ & $\mathbf{7 2} \mathrm{h}$ & $\mathbf{1 2 0} \mathrm{h}$ & At discharge (23rd day) \\
\hline Serum glucose $(60-110 \mathrm{mg} / \mathrm{dL})$ & 324 & 272 & 238 & 227 & 170 & 108 \\
\hline Ketonemia $(<0.6 \mu \mathrm{mol} / \mathrm{L})$ & 4.5 & 3.4 & 4.2 & 3.6 & 0.5 & 0.2 \\
\hline Triglycerides $(<200 \mathrm{mg} / \mathrm{dL})$ & 4797 & 746 & 628 & 431 & 314 & 272 \\
\hline
\end{tabular}

\section{TABLE 2: Time course of biochemical data.}

\section{Discussion}


Diabetic ketoacidosis results from insulin deficiency, increased lipolysis, and decreased activity of the lipoprotein lipase enzyme in the capillary endothelial cells of the adipose tissue. As a consequence, elevate circulating triglycerides can generate a higher concentration of FFA which contributes to pancreatic cell injury triggering AP [8]. It is important to consider that abdominal pain is common in severe DKA and serum amylase and lipase may show false-normal values in hyperlipemic serum or increased levels in $16 \%-25 \%$ of DKA patients without AP involvement [5,15]. Thus, physicians have to suspect AP in the presence of lactescent serum and persisting abdominal pain confirming the pancreatic damage with radiological images [16]. On admission, our patient presented many risk factors such as obesity, familiar hypertriglyceridemia, sedentary lifestyle, and excessive sugar-sweetened soft drinks daily intake. Classical triad of DKA-HTG-AP was confirmed, a rare evidence described with $11 \%$ prevalence in overall AP patients, unfortunately associated with higher rate of inpatient mortality, multiorgan failure, parental nutrition requirement, hospital charges, and longer hospital length of stay [17]. Moreover, the association of negative autoimmune markers and good $\beta$-cell function assigned a $54 \%$ probability of developing ketones in our patient [3]. Thus, prevention of the next episode, once HTG-induced AP episode has been resolved, is mandatory [18]. In recent years, the role of soft drinks consumption in glucose dysregulation has emerged in the Asiatic population with evidence of pancreatic $\beta$ cells dysfunction correlated with prediabetes, DM, and DKA (soft drink ketosis) $[6,10-13,19]$. Tanaka et al. have suggested that a polymorphism in the $\beta$-3adrenergic receptor gene (Ttrp64 homozygosis), involved in lipolysis, would be strictly associated with soft drink ketosis [11]. Currently, no evidence between soft drink ketosis and Caucasian patients has been found.

\section{Conclusions}

We reported the case of a Caucasian obese patient with two uncommon characteristics such as a rare triad of DKA-HTG-AP and soft drinks abuse, a metabolic condition more typical in patients from Asia compared to Western countries origin. Thus, physicians have to discourage soft drinks abuse in patients presenting with DM risk factors or diagnosis. Lifestyle changes consisting of dietary modifications and physical activity, beyond drug therapy, are the key behind successful management of DM and hyperlipidemia.

\section{Additional Information \\ Disclosures}

Human subjects: Consent was obtained by all participants in this study. Conflicts of interest: In compliance with the ICMJE uniform disclosure form, all authors declare the following: Payment/services info: All authors have declared that no financial support was received from any organization for the submitted work. Financial relationships: All authors have declared that they have no financial relationships at present or within the previous three years with any organizations that might have an interest in the submitted work. Other relationships: All authors have declared that there are no other relationships or activities that could appear to have influenced the submitted work.

\section{References}

1. Umpierrez GE, Khajavi M, Kitabchi AE: Diabetic ketoacidosis and hyperglycemic hyperosmolar nonketotic syndrome. Am J Med Sci. 1996, 311:225-233. 10.1097/00000441-199605000-00006

2. Delaney MF, Zisman A, Kettyle WM: Diabetic ketoacidosis and hyperglycemic hyperosmolar nonketotic syndrome. Endocrinol Metab Clin North Am. 2000, 29:683-705. 10.1016/s0889-8529(05)70159-6

3. Umpierrez GE, Smiley D, Kitabchi AE: Narrative review: ketosis-prone type 2 diabetes mellitus . Ann Intern Med. 2006, 144:350-357.

4. Umpierrez GE, Casals MM, Gebhart SP, Mixon PS, Clark WS, Phillips LS: Diabetic ketoacidosis in obese African-Americans. Diabetes. 1995, 44:790-795. 10.2337/diab.44.7.790

5. Nair S, Yadav D, Pitchumoni CS: Association of diabetic ketoacidosis and acute pancreatitis: observations in 100 consecutive episodes of DKA. Am J Gastroenterol. 2000, 95:2795-2800.

6. Tanaka M, Miyazaki Y: Diabetic ketoacidosis induced by excessive intake of soft drink complicated by hypercalcemia, hypertriglyceridemia and painless acute pancreatitis in a case of type 2 diabetes mellitus. J Jpn Diab Soc. 2001, 44:913-916.

7. Soejima S, Umeno Y, Fujita T, Dohmen K, Miyamoto Y: A case of diabetic ketoacidosis complicated by severe hypertriglyceridemia and acute pancreatitis. J Jpn Diab Soc. 2000, 43:561-566.

8. Yang F, Wang Y, Sternfeld L, et al.: The role of free fatty acids, pancreatic lipase and Ca+ signalling in injury of isolated acinar cells and pancreatitis model in lipoprotein lipase-deficient mice. Acta Physiol (Oxf). 2009, 195:13-28. 10.1111/j.1748-1716.2008.01933.x

9. Berglund L, Brupzell JD, Goldberg AC, et al.: Evaluation and treatment of hypertriglyceridemia: an endocrine Society clinical practice guideline. J Clin Endocrinol Metabol. 2015, 100:4685.

10. Nagasaka S, Ishikawa S, Itabashi N, Rokkaku K, Saito T: Ketoacidosis-onset type 2 diabetes in Japanese. Association with the widespread distribution of soft drinks and vending machines. Diabetes Care. 1998, 21:1376-1378. 10.2337/diacare.21.8.1376

11. Tanaka K, Moriya T, Kanamori A, Yajima Y: Analysis and a long-term follow up of ketosis-onset Japanese NIDDM patients. Diabetes Res Clin Pract. 1999, 44:137-146. 10.1016/s0168-8227(99)00023-6

12. Yamada K, Nonaka K: Diabetic ketoacidosis in young obese Japanese men . Diabetes Care. 1996, 19:671. 10.2337/diacare.19.6.671a

13. Yoshida M, McKeown NM, Rogers G, Meigs JB, Saltzman E, D'Agostino R, Jacques PF: Surrogate markers of insulin resistance are associated with consumption of sugar-sweetened drinks and fruit juice in middle and older-aged adults. J Nutr. 2007, 137:2121-2127. 10.1093/jn/137.9.2121 


\section{Cureus}

14. Beltramello G, Manicardi V, Trevisan R: Trialogue: managing hyperglycaemia in internal medicine: instructions for use. Acta Diabetol. 2013, 50:465-473. 10.1007/s00592-013-0462-1

15. Warshaw AL, Bellini CA, Lesser PB: Inhibition of serum and urine amylase activity in pancreatitis with hyperlipemia. Ann Surg. 1975, 182:72-75. 10.1097/00000658-197507000-00014

16. Fujishiro M, Horita A, Nakagawara $\mathrm{H}$, et al.: Severe hypertriglyceridemia possibly masked acute pancreatitis and led to a difficult diagnosis in an obese patient with ketoacidosis-onset type 2 diabetes. Intern Med. 2017, 56:2611-2616. 10.2169/internalmedicine.8474-16

17. Simons-Linares CR, Jang S1, Sanaka M, et al.: The triad of diabetes ketoacidosis, hypertriglyceridemia and acute pancreatitis. How does it affect mortality and morbidity? A 10-year analysis of the National Inpatient Sample. Medicine (Baltimore). 2019, 98:e14378. 10.1097/MD.0000000000014378

18. Valdivielso P, Ramírez-Bueno A, Ewald N: Current knowledge of hypertriglyceridemic pancreatitis . Eur J Intern Med. 2014, 25:689-694. 10.1016/j.ejim.2014.08.008

19. Ma J, McKeown NM, Hwang SJ, Hoffmann U, Jacques PF, Fox CS: Sugar-sweetened beverage consumption is associated with change of visceral adipose tissue over 6 years of follow-up. Circulation. 2016, 26:370-377 